\title{
Dessecação Pré-Colheita e Efeitos sobre a Produtividade e Qualidade Fisiológica de Sementes de SoJA ${ }^{1}$
}

\author{
Pre-Harvest Application and Effects on Yield and Physiological Quality of Soybean Seeds
}

\author{
LAMEGO, F.P. ${ }^{2}$, GALLON, M. ${ }^{2}$, BASSO, C.J. ${ }^{2}$, KULCZYNSKI, S.M. ${ }^{2}$, RUCHEL, Q. ${ }^{3}$, KASPARY, T.E. ${ }^{2}$ e \\ SANTI, A.L. ${ }^{2}$
}

\begin{abstract}
RESUMO - A antecipação da colheita da soja é possível com uso da prática de dessecação pré-colheita, a qual reduz o tempo de permanência das sementes no campo, após a maturação fisiológica. O objetivo deste trabalho foi avaliar o efeito da época de aplicação do herbicida paraquat, como dessecante na pré-colheita da soja, sobre a produtividade e qualidade fisiológica de sementes. O trabalho constou de duas etapas: um experimento em campo, conduzido no município de Jaboticaba-RS, safra 2010/2011, e uma análise da qualidade fisiológica das sementes. Os tratamentos consistiram de três épocas de aplicação do paraquat (240 g i.a. ha-1), R6, R7.1 e R7.3, bem como de um tratamento testemunha (sem dessecação). Foram avaliados a produtividade de grãos e os componentes da produtividade. A análise da qualidade das sementes foi conduzida no Laboratório de Produção e Tecnologia de Sementes da UFSM, Campus de Frederico Westphalen, RS, onde se realizaram os seguintes testes: germinação; primeira contagem de germinação, comprimento de parte aérea e radicular, matéria seca de plântulas, envelhecimento acelerado, condutividade elétrica, emergência em campo e índice de velocidade de emergência. A aplicação de paraquat como dessecante na pré-colheita da soja, nos estádios R6 e R7.1, provoca queda acentuada na produtividade da cultura. A dessecação sem perda de potencial produtivo da soja só é viável a partir do estádio R7.3. Sementes oriundas de plantas com dessecação nos estádios R6 e R7.1 apresentam percentual superior e maior velocidade de germinação. Entretanto, sementes de plantas com dessecação no estádio R6 possuem menor vigor de plântulas.
\end{abstract}

Palavras-chave: Glycine max, paraquat, estádio fenológico, vigor de sementes.

\begin{abstract}
The anticipation of soybean harvest is possible with the use of pre-harvest burn-down practice, which reduces the time of permanence of seeds in the field, after reaching physiological maturation. The objective of this work was to evaluate the effect of time of application of the herbicide paraquat as burn-down during soybean pre harvest on yield and physiological quality of the seeds. The work consisted of two steps: one field experiment, conducted in Jaboticaba-RS, in 2010/2011 and the analysis of the physiological quality of seeds. The treatments consisted of three times of paraquat (240 g a.i. ha ${ }^{-1}$ ) application, R6, R7.1 and R7.3, as well as one untreated (without burn-down). Yield grains and yield components were evaluated. Seed quality analysis was conducted at the Seed Production and Technology Laboratory of UFSM, Campus of Frederico Westphalen, RS, where the following evaluations were carried out: germination, first germination count, root and shoot weight, shoot dry mass of seedlings, accelerated aging, electrical conductivity, field emergence and emergence velocity index. Paraquat application as burn-down practice in soybean pre harvest, at the R6 and R7.1 soybean stages, causes high yield loss in soybean crop. Burn-down without potential yield loss is only viable after R7.3 soybean growth stage. Seeds originated from plants which received paraquat application in $R 6$ and R7.1, show a superior percentile of germination and a higher germination velocity. However, seeds from plants which received paraquat at stage $R 6$ have less seed vigor.
\end{abstract}

Keywords: Glycine max, paraquat, growth stage, seed vigor.

1 Recebido para publicação em 27.9.2012 e aprovado em 24.1.2013.

2 Universidade Federal de Santa Maria - UFSM, Santa Maria-RS, Brasil, <fabilamego@yahoo.com.br>; ${ }^{3}$ Universidade Federal de Pelotas, Pelotas-RS, Brasil. 


\section{INTRODUÇÃO}

A soja (Glycine max) é a mais importante oleaginosa cultivada no mundo; seu alto teor de proteínas, que proporciona múltiplas utilizações, e os usos industriais não tradicionais, como biodiesel, tintas, vernizes, entre outros, aumentarão a demanda do produto. Essa cultura também tem grande importância na produção de alimentos, sendo fonte de matéria-prima para a indústria e alimentação animal, com ampla adaptação às condições brasileiras. Atualmente, o Brasil ocupa a posição de segundo maior produtor mundial de soja, apresentando números da ordem de 75 milhões de toneladas produzidas na safra 2010/11, em 24,2 milhões de hectares (ha) cultivados (Embrapa, 2012).

O processo de maturação da semente de uma planta compreende uma série de alterações morfológicas, fisiológicas e funcionais que ocorrem a partir da fertilização do óvulo, prosseguindo até o momento em que as sementes estão em condições para a colheita (Delouche, 1971). Durante o processo de formação e maturação das sementes, são verificadas alterações na massa da matéria seca, grau de umidade, tamanho, germinação e vigor, sendo a maior qualidade fisiológica observada no estádio denominado maturidade fisiológica (Carvalho \& Nakagawa, 2000) ou, em soja, o estádio R7 (Fehr \& Caviness, 1977). A maturidade fisiológica caracteriza o momento em que a semente não depende mais fisiologicamente da planta e passa a sofrer maior influência das condições ambientais (Marcos Filho, 1986).

Após a maturação fisiológica, pode-se considerar a semente armazenada em campo, enquanto a colheita não é processada (Costa et al., 1983). De modo geral, é possivel afirmar que a qualidade das sementes decresce a partir da maturidade fisiológica, dependendo das condições climáticas, principalmente em função da temperatura e da umidade relativa do ambiente em que ficam expostas, até o momento de serem colhidas (Garcia et al., 2004).

O potencial de conservação de sementes de soja depende diretamente da qualidade fisiológica destas no início do período de armazenamento, estando intimamente relacionado ao momento em que a colheita é realizada (Silva Castro, 1989; Lacerda et al., 2003). Harrington (1972) afirma que o armazenamento de sementes, ao contrário do que comumente se pensa, não começa após a chegada da semente no armazém, e sim desde o momento em que atinge a maturidade fisiológica ainda no campo. Esse "período de armazenamento" das sementes em campo é decisivo para a deterioração ou perda de vigor (Delouche, 1975).

De modo geral, o atraso da colheita, associado à variação da umidade relativa do ar, acarreta vários prejuízos às sementes, como o aumento das porcentagens de rachadura e enrugamento do tegumento, aumentando o processo de deterioração, em virtude de maior facilidade de penetração de patógenos e maior exposição do tecido embrionário ao ambiente (Marcandalli et al., 2011). Assim, todos os procedimentos que possam contribuir para a preservação da qualidade fisiológica das sementes são benéficos. Entre eles está a antecipação da colheita, tendo como uma das alternativas o uso de herbicidas dessecantes (Daltro et al., 2010).

A antecipação da colheita da soja só é possivel usando-se herbicidas dessecantes, e o grau de dessecação está diretamente relacionado com a injúria causada pelo produto à membrana da célula no tecido folhar, permitindo rápida perda de água (Lacerda et al., 2001). Dessa forma, o emprego dessa prática tem como vantagens adicionais a possibilidade de planejamento da colheita, maior eficiência das máquinas, controle de plantas daninhas que prejudicam o processo de colheita e redução dos danos oriundos de pragas e fungos que possam atacar a cultura no final do ciclo (Marcos Filho, 2005). Ainda, com o aumento do número de cultivos nas áreas agrícolas visando maior rendimento por área, o período entre a semeadura e a colheita está se tornando cada vez mais curto e, por ter a soja uma maturidade fisiológica desuniforme, o uso de herbicidas dessecantes para antecipação da colheita tem aumentado continuamente (Marcandalli et al., 2011).

De acordo com Embrapa (2012), a dessecação da soja é uma prática que pode ser adotada somente em área de produção de grãos, com o objetivo de controlar as plantas daninhas 
ou uniformizar as plantas com problemas de haste verde/retenção foliar. No entanto, diversos resultados positivos têm sido obtidos em relação à eficácia de dessecantes quanto à preservação da qualidade de sementes de soja (Durigan \& Carvalho, 1980; Lacerda et al., 2003; Pelúzio et al., 2008; Kappes et al., 2009).

A decisão sobre o momento adequado para aplicar o dessecante é o ponto principal da operação de dessecação na pré-colheita. Sua aplicação antecipada pode resultar em perdas consideráveis na produtividade da soja, interferindo na germinação e no vigor das sementes colhidas. Por outro lado, a aplicação tardia não apresentará resultados significativos na antecipação da colheita, frustrando o objetivo principal da operação.

O principal herbicida utilizado nas operações de dessecação da soja para antecipação da colheita tem sido o paraquat. Segundo Vargas \& Roman (2006), o paraquat é um herbicida não seletivo, utilizado em pós-emergência, com reduzida translocação na planta (de contato) e de baixa persistência no solo, sendo usado para controle total da vegetação.

O objetivo deste trabalho foi avaliar o efeito da época de aplicação de paraquat, como herbicida dessecante na pré-colheita da soja, sobre a produtividade e a qualidade fisiológica de sementes.

\section{MATERIAL E MÉTODOS}

O trabalho foi realizado em duas etapas: uma em campo e a outra em laboratório. Em campo foi desenvolvido um experimento, em uma área experimental no município de Jaboticaba-RS, região do Médio e Alto Uruguai do RS, entre as coordenadas geográficas de $53^{\circ}$ 17' 59" (O) e 27० 40' 27" (S), aproximadamente $519 \mathrm{~m}$ de altitude, $1.710 \mathrm{~mm}$ de precipitação média anual e $20,3{ }^{\circ} \mathrm{C}$ de temperatura média anual (ano agrícola 2010/2011).

O solo da área é caracterizado como Latossolo Vermelho distrófico típico (Embrapa, 1999). A semeadura de forma direta do cultivar de soja Energia RR (Brasmax Genética) foi realizada no dia 29/10/2010, num espaçamento de 0,45 m entre linhas, com população aproximada de 32 plantas $\mathrm{m}^{-2}$. A adubação química utilizada foi $250 \mathrm{~kg} \mathrm{ha}^{-1}$ da fórmula
0-18-18 (N-P-K), seguindo recomendação da CQFSRS/SC (2004).

O delineamento utilizado foi o de blocos ao acaso com quatro repetições. As parcelas experimentais tinham dimensões de 5,0 x $4,5 \mathrm{~m}$. As avaliações foram realizadas nas quatro linhas centrais da parcela, excluindose 1,0 m de bordadura. Os tratamentos consistiram de três épocas de dessecação, as quais corresponderam a três estádios de desenvolvimento da soja: R6 (vagens com granação de $100 \%$ e folhas verdes - 111 dias após a semeadura - DAS ), R7.1 (início a 50\% de amarelecimento de folhas e vagens - 119 DAS), R7.3 (plantas com mais de $76 \%$ de folhas e vagens amarelas - 124 DAS) (Ritchie,1977) e uma testemunha (sem dessecação).

O herbicida utilizado como dessecante foi o paraquat, na dose de 240 g i.a. ha ${ }^{-1}$, acrescido de espalhante adesivo na proporção de 0,01\% $\mathrm{v} / \mathrm{v}$. Os tratamentos foram aplicados com aspersor pressurizado a $\mathrm{CO}_{2}$, usando-se uma barra com quatro pontas de pulverização tipo leque (modelo XR 110-02 VP), a $200 \mathrm{kPa}$ de pressão e $200 \mathrm{~L} \mathrm{ha}^{-1}$ de volume de calda.

A colheita da soja foi feita manualmente no dia 9/3/2011, em uma área útil de 5,4 $\mathrm{m}^{2}$. Todos os tratamentos foram colhidos no mesmo dia e, posteriormente, foram determinados a produtividade de grãos e seus componentes (peso de mil sementes, número total de legumes fixados, número de legumes com um, dois, três e quatro grãos e número total de grãos por planta), bem como a estatura de planta, número de nós férteis na haste principal e número de nós férteis nos ramos laterais, em oito plantas escolhidas aleatoriamente dentro da área útil.

A segunda etapa do trabalho, referente às análises da qualidade das sementes, foi realizada no Laboratório de Produção e Tecnologia de Sementes da Universidade Federal de Santa Maria, UFSM, Campus de Frederico Westphalen, RS. Nesta etapa foram realizadas as seguintes análises: germinação (Brasil, 2009); primeira contagem da germinação (Krzyzanowski et al., 1999); envelhecimento acelerado (AOSA, 1983); condutividade elétrica (Vieira, 1994); comprimento de parte aérea e sistema radicular; peso de matéria seca de plântulas; emergência de plântulas em campo 
(Nakagawa, 1999); e indice de velocidade de emergência (Maguire,1962).

Os valores das análises de sementes, bem como da parte realizada em campo, que não atenderam aos requisitos de distribuição normal e de homogeneidade de variâncias foram transformados utilizando-se $\sqrt{ } \mathrm{x}+1$. Os dados foram submetidos à análise de variância; havendo significância, os tratamentos foram comparados pelo teste de Duncan a 5\% $(\mathrm{p} \leq 0,05)$ de probabilidade.

\section{RESULTADOS E DISCUSSÃO}

O rendimento de grãos foi significativamente afetado pela dessecação, nos primeiros estádios da soja (Tabela 1). Com a aplicação de paraquat no estádio $\mathrm{R} 6$, a redução na produtividade foi de aproximadamente 35\%, quando comparada à da testemunha, que produziu $4.221 \mathrm{~kg} \mathrm{ha}^{-1}$. Quando a dessecação ocorreu no estádio R7.1, a redução na produtividade de grãos foi menor, porém ainda estatisticamente significativa, com $3.668 \mathrm{~kg} \mathrm{ha}^{-1}$, ou seja, $13 \%$ a menos que a testemunha. Já para a dessecação no estádio R7.3, não houve diferença significativa para a produtividade quando comparada à da testemunha, mostrandose superior aos demais tratamentos, com valor equivalente a $4.076 \mathrm{~kg} \mathrm{ha}^{-1}$.

Os resultados observados neste estudo mostraram-se contrários aos observados por Ritchie et al. (1977), em que, a partir do estádio R7, a produtividade de grãos da soja não foi mais afetada pela dessecação. Entretanto, ensaios conduzidos por Fonseca (1984) mostraram que a produção de sementes aumentou à medida que as aplicações de paraquat foram feitas mais próximas da maturação fisiológica de colheita (R8), atingindo o máximo em torno do estádio R7.5.

Em trabalho com diferentes épocas de dessecação de dois cultivares de soja com o herbicida paraquat, foram observadas reduções de produtividade quando comparada à dessecação no estádio R6 com a testemunha que não recebeu aplicação do dessecante, sendo estas de 34\% para o cultivar Savana e de $32 \%$ para o Doko (Nakashima et al., 2000). Pelúzzio (2008) e Lacerda (2001) também detectaram reduções significativas de produção quando a dessecação foi realizada no estádio R6. Segundo Pelúzzio (2008), isso se justifica provavelmente pelo fato de a planta ainda estar translocando fotoassimilados para a semente; com a dessecação, ocorre paralisação desse fornecimento e consequente decréscimo na produtividade.

Com relação aos componentes da produtividade da soja, para o PMS (Tabela 1), no estádio de dessecação R6, observou-se redução de $33,5 \%$ de PMS quando comparada à da testemunha, sendo esse de 114,37 g. Quando a dessecação foi realizada em R7.1, o PMS ficou intermediário, sendo superior, estatisticamente, à dessecação no estádio R6, mas inferior à do estádio R7.3 e da testemunha. As dessecações no estádio R7.3 e na testemunha proporcionaram PMS de 167,46 e 172,07 g, respectivamente, mostrando-se superiores às dos demais tratamentos.

Tabela 1 - Produtividade de grãos, peso de mil sementes (PMS) e teste de germinação (TG) de soja, sob efeito da aplicação de dessecante paraquat (240 g i.a. ha ${ }^{-1}$ ), em diferentes estádios na pré-colheita da soja, cv. Energia RR. Jaboticaba, RS, e UFSM, Campus de Frederico Westphalen, RS, 2010/11

\begin{tabular}{|c|c|c|c|c|c|c|}
\hline \multirow{2}{*}{$\begin{array}{l}\text { Época de } \\
\text { dessecação }\end{array}$} & \multirow{2}{*}{$\begin{array}{c}\text { Produtividade de } \\
\text { grãos } \\
\left(\mathrm{kg} \mathrm{ha}^{-1}\right)\end{array}$} & \multirow{2}{*}{$\begin{array}{l}\text { PMS } \\
(\mathrm{g})\end{array}$} & \multicolumn{4}{|c|}{ Teste de Germinação (\%) } \\
\hline & & & Normais & Anormais & Mortas & Duras \\
\hline Test. ${ }^{1 /}$ & $4.221 \mathrm{~A}^{\frac{3}{}}$ & $172,07 \mathrm{~A}$ & $84,00 \mathrm{~B}$ & $11,00 \mathrm{~A}$ & $5,00 \mathrm{~A}$ & $0,00 \mathrm{~A}$ \\
\hline R 7.3 & $4.076 \mathrm{~A}$ & $167,46 \mathrm{~A}$ & $82,25 \mathrm{~B}$ & $8,25 \mathrm{~A}$ & $9,25 \mathrm{~A}$ & $0,00 \mathrm{~A}$ \\
\hline R 7.1 & $3.668 \mathrm{~B}$ & $152,40 \mathrm{~B}$ & $90,25 \mathrm{~A}$ & $7,25 \mathrm{~A}$ & $1,50 \mathrm{~B}$ & $1,00 \mathrm{~A}$ \\
\hline $\mathrm{R} 6.0$ & $2.751 \mathrm{C}$ & $114,37 \mathrm{C}$ & $88,75 \mathrm{~A}$ & $8,75 \mathrm{~A}$ & $1,75 \mathrm{~B}$ & $0,75 \mathrm{~A}$ \\
\hline $\mathrm{CV}^{2 /}(\%)$ & 7,01 & 4,48 & 2,41 & 18,75 & 33,01 & 31,12 \\
\hline
\end{tabular}

1/ Sem aplicação de dessecante. ${ }^{2}$ Coeficiente de variação. ${ }^{3 /}$ Médias seguidas de letras idênticas, nas colunas, não diferem entre si pelo teste de Duncan a $5 \%$ de probabilidade. 
Comparando os dados da produtividade de grãos e do PMS, percebe-se a estreita relação que essas duas variáveis apresentam, sendo o PMS geralmente o componente que mais explica a produtividade. Em estudo realizado por Lacerda (2001), o efeito de épocas de dessecação também foi significativo para o PMS, evidenciando que a menor produção obtida também ocorreu na mesma época em que se obteve menor PMS. Pelúzzio (2008) também obteve em seus experimentos quedas significativas do PMS em dessecações nos estádios R6 e R7 da soja. Entretanto, Malaspina (2008) não observou diferenças para essa variável entre as épocas de dessecação avaliadas.

Quanto a estatura de planta, número de nós férteis na haste principal, número de nós férteis nos ramos laterais, número total de nós férteis, número total de legumes fixados, número de legumes com um, dois, três e quatro grãos e número total de grãos por planta, não foram observadas diferenças significativas entre os tratamentos (dados não apresentados), evidenciando que as plantas já se encontravam com essas variáveis plenamente desenvolvidas a partir da primeira época de aplicação do dessecante.

Para o teste de germinação (Tabela 1), percebe-se que o percentual de germinação diminuiu com o atraso nas dessecações. Analisando a porcentagem de plântulas normais, observa-se que sementes oriundas dos estádios R7.1 e R6 de dessecação foram superiores às demais, apresentando 90,25 e 88,75\% de germinação, respectivamente, enquanto a testemunha obteve $84,00 \%$ e, no estádio R7.3, $82,25 \%$. Esses resultados mostram-se semelhantes aos de McNeal et al. (1973), que concluíram que a aplicação de dessecantes em estádios mais precoces na cultura da soja provoca melhoria no poder germinativo das sementes.

Os resultados obtidos por Pelúzio (2008) confirmam maiores taxas de germinação quando a dessecação da cultura ocorreu nos estádios R6 e R7 e colhida na época R8 (maturação de colheita), decrescendo a partir daí, independentemente da época de colheita. Entretanto, Malaspina (2008) verificou que sementes de plantas dessecadas nos estádios de desenvolvimento R7 e R8 apresentaram maior porcentagem de germinação, sendo superiores às dessecadas no estádio R6. Daltro et al. (2010) observaram que o uso dos dessecantes paraquat, diquat, paraquat+diquat e paraquat+diuron não indicou variações importantes no potencial fisiológico das sementes produzidas, em relação àquelas não dessecadas. Cabe salientar que os valores obtidos no teste de germinação no presente estudo classificam a produção obtida em todos os tratamentos como adequada para a comercialização como semente, pois, conforme Embrapa (2005), a porcentagem mínima exigida como padrão para semente é de $80 \%$.

Para as variáveis plântulas anormais e sementes duras, não se observou diferença entre os tratamentos (Tabela 1). Contudo, observa-se que, para a porcentagem de plântulas mortas, novamente nos dois primeiros estádios de dessecação são observados os melhores resultados, ou seja, menor porcentagem delas, sendo 1,75\% para dessecação em R6 e 1,50\% para R7.1, ao passo que para R7.3 e a testemunha foram observados 9,25 e 5\%, respectivamente. Os altos indices de plantas mortas observados para a testemunha e dessecação no estádio R7.1 explicam a baixa porcentagem de germinação obtida para esses mesmos tratamentos.

Em trabalho realizado por Gomes et al. (1982), foi observado aumento na porcentagem de plântulas normais e redução de plântulas anormais e mortas quando os dessecantes foram aplicados nos estádios próximos da maturação fisiológica. Whigan \& Stoleer (1979), trabalhando com três épocas de aplicação, verificaram que o herbicida paraquat, quando aplicado quatro e três semanas antes da colheita, não prejudicou a germinação e o vigor das sementes.

Em relação à qualidade fisiológica das sementes, analisando a Primeira Contagem de Germinação (PCG) (Tabela 2), percebe-se que nos estádios de dessecação R6 e R7.1 houve superioridade em relação aos demais, com percentual de germinação de 97,50 e 96,75\%, respectivamente. Quando da dessecação em R7.3 e testemunha, observou-se germinação de 91 e 94\%, respectivamente, não diferindo estatisticamente entre si. Portanto, as sementes oriundas dos estádios R6 e R7.1, de acordo com a PCG, mostraram-se inicialmente mais vigorosas que as demais, pois, 
Tabela 2 - Primeira contagem de germinação (PCG), comprimento de parte aérea (CPA), comprimento radicular (CRD), comprimento de plântulas (CPL) e massa seca de plântulas (MSP) de soja, cv. Energia RR, sob efeito de aplicação de paraquat como dessecante (240 g i.a. ha-1), em diferentes estádios na pré-colheita. UFSM, Campus de Frederico Westphalen, RS, 2010/11

\begin{tabular}{|c|c|c|c|c|c|}
\hline Época de dessecação & PCG $(\%)$ & CPA $(\mathrm{mm})$ & CRD (mm) & $\begin{array}{c}\text { CPL } \\
(\mathrm{mm})\end{array}$ & $\begin{array}{c}\text { MSP } \\
\text { (mg por plântula) }\end{array}$ \\
\hline${\text { Test. }{ }^{1 /}}^{\prime}$ & $94,00 \mathrm{~B}^{3 /}$ & $64,90 \mathrm{~B}^{3 /}$ & $71,87 \mathrm{~B}$ & $136,77 \mathrm{~B}$ & $121,25 \mathrm{~A}$ \\
\hline $\mathrm{R} 7.3$ & $91,00 \mathrm{~B}$ & $65,55 \mathrm{~B}$ & $89,81 \mathrm{~A}$ & $155,36 \mathrm{~A}$ & $131,87 \mathrm{~A}$ \\
\hline $\mathrm{R} 7.1$ & $96,75 \mathrm{~A}$ & $64,77 \mathrm{~B}$ & $91,96 \mathrm{~A}$ & $156,73 \mathrm{~A}$ & $120,75 \mathrm{~A}$ \\
\hline $\mathrm{R} 6$ & $97,50 \mathrm{~A}$ & $75,38 \mathrm{~A}$ & $94,28 \mathrm{~A}$ & $169,66 \mathrm{~A}$ & $94,75 \mathrm{~B}$ \\
\hline $\mathrm{CV}^{2}{ }^{2}(\%)$ & 1,89 & 8,54 & 12,59 & 8,84 & 0,84 \\
\hline
\end{tabular}

1/ Sem aplicação de dessecante. ${ }^{2}$ Coeficiente de variação. ${ }^{3 /}$ Médias seguidas de letras idênticas, nas colunas, não diferem entre si pelo teste de Duncan a $5 \%$ de probabilidade.

quanto maior o número de plântulas normais computadas na data da primeira contagem, maior será o vigor do lote (Nakagawa, 1999).

Kappes et al. (2009) verificaram que as testemunhas que não receberam aplicação de dessecantes apresentaram as maiores velocidades de germinação. Já Durigan \& Carvalho (1980) não observaram diferença significativa na velocidade de germinação das sementes de soja dessecadas com paraquat em diferentes épocas. Em trabalho com dessecação de feijão, foi observado que, na dose de $200 \mathrm{~g}$ i.a. ha $\mathrm{h}^{-1} \mathrm{de}$ paraquat as sementes obtidas nas primeiras épocas de dessecação (mais precoces) mostraram-se mais vigorosas, também de acordo com a PCG (Kappes et al., 2012). A obtenção de sementes vigorosas é de fundamental importância, pois o nível de vigor pode afetar o estabelecimento da cultura, o desenvolvimento das plantas, a uniformidade da lavoura e a produtividade final (Carvalho \& Nakagawa, 2000).

Em relação ao peso de massa seca de plântulas, verificou-se que aquelas oriundas da dessecação no estádio R6 mostraram-se inferiores às dos demais tratamentos, com produção de 94,75 mg por plântula, sendo consideradas, portanto, menos vigorosas (Tabela 2). Isso, em parte, pode ser explicado pelo PMS, que, para o mesmo tratamento, foi inferior aos demais, mostrando que a dessecação em R6 originou sementes menores e com menor reserva, as quais originaram plântulas de menor tamanho e menor vigor, consequentemente. Para a testemunha e a dessecação nos estádios R7.1 e R7.3, não se observou diferença entre os tratamentos, apresentando massa seca de 121,25, 131,87 e 120,75 mg por plântula, respectivamente. Esses resultados concordam com os de Marcandalli et al. (2011), os quais verificaram que as sementes obtidas com aplicação de dessecantes no estádio $R_{6}$ são de qualidade fisiológica inferior à das obtidas com aplicação nos estádios R7 e R8.

Analisando o comprimento de parte aérea (Tabela 2), percebe-se que as plântulas originárias de sementes de soja dessecadas no estádio R6 foram estatisticamente superiores às dos demais tratamentos, apresentando comprimento de parte aérea de $75,38 \mathrm{~mm}$. A testemunha e a dessecação nos estádios R7.3 e R7.1 não diferiram entre si estatisticamente e apresentaram 64,90, 65,55 e 64,77 mm, respectivamente. Considerando-se o sistema radicular, as radículas provindas de sementes que não receberam aplicação de paraquat mostraram-se de tamanho inferior ao daqueles tratamentos, com $71,87 \mathrm{~mm}$; aquelas oriundas dos estádios R7.3, R7.1 e R6 de dessecação apresentaram 89,81, 91,96 e $94,28 \mathrm{~mm}$ de comprimento de radícula, respectivamente. O resultado para comprimento do sistema radicular foi estatisticamente semelhante ao obtido com o comprimento de plântulas, no qual, novamente, aquelas da testemunha se mostraram inferiores às dos demais tratamentos.

Kappes (2012), em trabalho realizado com feijão, verificou que a aplicação de paraquat aos 30 dias após o florescimento (DAF) proporcionou a obtenção de plântulas com maior tamanho de parte aérea, quando comparadas as plântulas oriundas de sementes dessecadas 
aos 45 DAF. Por sua vez, quando avaliado o comprimento total de plântula, não se verificou efeito de épocas de aplicação de paraquat. Já Malaspina (2008) e Daltro (2010) não observaram diferenças significativas para comprimento de radícula nas diferentes épocas de dessecação de soja avaliadas.

$\mathrm{Na}$ avaliação do vigor de sementes através do envelhecimento acelerado, verificou-se que as sementes oriundas da dessecação em R7.1 mostraram-se as menos vigorosas entre todos os tratamentos avaliados (Tabela 3). As sementes que não receberam aplicação de herbicida apresentaram os melhores resultados. Esses dados assemelham-se aos de Kappes (2009), que também observou que as sementes das testemunhas originaram maiores percentuais de plântulas normais no teste de envelhecimento acelerado. Todavia, Pelúzio (2008) observou em suas médias queda do vigor com o retardamento da colheita em todos os estádios de dessecação, sendo o maior vigor observado quando da dessecação no estádio R7.

Para o teste de condutividade elétrica (Tabela 3), não foi observada diferença significativa entre os tratamentos; embora as sementes provindas do estádio de dessecação R6 tenham mostrado, em magnitude, ser mais vigorosas que as demais, apresentaram o menor valor para o teste. Malaspina (2008) também observou menores valores de condutividade em sementes de plantas de soja dessecadas no estádio R6. Entretanto, Lacerda (2003) verificou valores de condutividade maiores em sementes armazenadas, provenientes de épocas de dessecação mais precoces.
Em estudo de sementes com condutividade elétrica abaixo de $60 \mu \mathrm{S} \mathrm{cm}^{-1} \mathrm{~g}^{-1}$, foi obtida alta porcentagem de emergência no solo, germinação e vigor, semelhante ao observado no presente experimento, onde as sementes que apresentaram valores de condutividade próximos ao estudado também se mostraram superiores aos demais tratamentos nas avaliações citadas (Sá \& Lazarini, 1995).

Os dados de emergência em campo e IVE (Tabela 3) foram semelhantes aos verificados no teste de germinação e na primeira contagem de germinação, evidenciando que as sementes obtidas da dessecação de plantas no estádio R6 apresentaram superioridade em relação aos demais tratamentos. Lacerda et al. (2003) não observaram diferença entre as sementes obtidas em quatro épocas de dessecação da soja, quando avaliada a emergência em campo.

Durigan \& Carvalho (1980) não observaram diferença significativa na velocidade de emergência das sementes de soja dessecadas com paraquat em diferentes épocas. Já Kappes et al. (2009) verificaram que o tratamento testemunha proporcionou sementes com IVE maior quando comparadas àquelas oriundas de dessecação nos estádios R6, R7.1 e R7.2. Entretanto, em outro trabalho com feijão, Kappes et al. (2012) observaram que, quando foram aplicados 200 e 600 g i.a. ha ha $^{-1}$ de paraquat, as aplicações realizadas precocemente aos 30, 35 e 40 DAF favoreceram a rápida emergência das sementes. Gomes (1982), utilizando paraquat e mistura de paraquat + diquat, usando paraquat na dessecação de soja, obteve sementes de melhor

Tabela 3 - Envelhecimento acelerado, condutividade elétrica, emergência em campo e índice de velocidade de emergência (IVE) de soja, cv. Energia RR, sob efeito de aplicação de paraquat como dessecante (240 g i.a. ha-1), em diferentes estádios na pré-colheita da cultura. UFSM, Campus de Frederico Westphalen, RS, 2010/11

\begin{tabular}{|c|c|c|c|c|}
\hline $\begin{array}{c}\text { Época de } \\
\text { dessecação }\end{array}$ & $\begin{array}{c}\text { Envelhecimento } \\
\text { acelerado }(\%)\end{array}$ & $\begin{array}{c}\text { Condutividade elétrica } \\
\left(\mu \mathrm{S} \mathrm{cm}^{-1} \mathrm{~g}^{-1}\right)\end{array}$ & $\begin{array}{c}\text { Emergência em campo } \\
(\%)\end{array}$ & IVE \\
\hline Test. $^{1 /}$ & $94,00 \mathrm{~A}^{3 /}$ & $73,08 \mathrm{~A}$ & $87,50 \mathrm{~B}$ & $5,46 \mathrm{~B}$ \\
\hline R7.3 & $85,00 \mathrm{BC}$ & $82,33 \mathrm{~A}$ & $87,50 \mathrm{~B}$ & $5,32 \mathrm{~B}$ \\
\hline $\mathrm{R} 7.1$ & $81,00 \mathrm{C}$ & $84,33 \mathrm{~A}$ & $86,00 \mathrm{~B}$ & $5,40 \mathrm{~B}$ \\
\hline $\mathrm{R} 6$ & $92,00 \mathrm{AB}$ & $68,40 \mathrm{~A}$ & $93,00 \mathrm{~A}$ & $6,11 \mathrm{~A}$ \\
\hline $\mathrm{CV}^{2}$ - $(\%)$ & 5,49 & 8,53 & 3,36 & 4,29 \\
\hline
\end{tabular}

1 Sem aplicação de dessecante. ${ }^{2}$ Coeficiente de variação. ${ }^{3 /}$ Médias seguidas de letras idênticas, nas colunas, não diferem entre si pelo teste de Duncan a 5\% de probabilidade. 
qualidade, se comparada com as que não sofreram dessecação.

Segundo Roman et al. (2001), pesquisas confirmam que a dessecação pré-colheita não diminui a germinação das sementes; pelo contrário, adotando-se essa prática, o poder germinativo é incrementado. Testes conduzidos no Brasil mostraram que a porcentagem de germinação de sementes das plantas não dessecadas foi menor quando comparada com a das tratadas. Além disso, sementes obtidas de parcelas não tratadas apresentaram elevado nível de infecção por microrganismos (Aspergillus sp. e Fusarium sp.) e de danos, quando comparadas com as sementes provenientes de parcelas dessecadas.

De maneira geral, a dessecação da soja nos estádios R6 e R7.1 proporcionou redução decrescente da produtividade de grãos - explicada pelo componente da produtividade PMS, o qual foi inferior nas sementes oriundas desses tratamentos. Em relação à qualidade fisiológica das sementes, observou-se que, independentemente das épocas de dessecação, os testes de germinação mostraram valores superiores a $80 \%$. Todavia, apenas o teste de vigor expresso pelo peso da massa seca de plântulas para aquelas sementes oriundas de R6 concorda com o resultado observado em campo, ou seja, sementes oriundas da dessecação neste estádio acumularam menos reservas, comprovado pelo menor PMS, e, consequentemente, apresentaram menor vigor. Contudo, os testes de vigor de comprimento de parte aérea, sistema radicular e de plântula, de emergência em campo e de IVE indicaram superioridade de sementes oriundas de R6, inclusive quando comparadas à testemunha, sem dessecação. Embora a colheita tenha sido realizada na mesma época, sementes de dessecação mais tardia da soja ou da testemunha ficaram por maior periodo de tempo no campo, expostas a condições adversas de umidade e temperatura. Esse fato também foi evidenciado por Lacerda et al. (2005) e está de acordo com Giurizatto et al. (2003), os quais afirmaram que a taxa de deterioração das sementes é aumentada consideravelmente pela exposição às condições adversas de temperatura e umidade relativa, resultando em menor vigor das sementes.
Em experimento com armazenamento de sementes dessecadas, Lacerda et al. (2003) observaram que aquelas oriundas de plantas dessecadas com o herbicida paraquat em épocas mais precoces obtiveram maior percentual de germinação, não diferindo entre si o teste de germinação realizado na pós-colheita e com as sementes armazenadas por seis meses.

A deterioração manifesta-se no decorrer do tempo, ocasionando reflexos negativos no vigor. A rapidez com que ocorre a perda de qualidade das sementes após a maturidade fisiológica é função da espécie, do cultivar e das condições impostas às sementes no campo, após a colheita e durante as operações de beneficiamento e armazenamento (Marcandalli et al., 2011).

Outros fatores a considerar seriam o tempo da colheita, o armazenamento das sementes e a realização dos testes de qualidade fisiológica, o que equivaleu a, pelo menos, seis meses. Embora todas as amostras tenham sido acondicionadas em condições semelhantes, pode ter havido deterioração em algum nivel das sementes oriundas dos demais tratamentos, quando em comparação com as sementes oriundas do estádio de dessecação R6.

\section{AGRADECIMENTOS}

À família Santi, em especial ao sr. Valdomiro Pigatto Santi e sr. Isaldo Ângelo Dalbianco, pela concessão da área e pelo auxílio na condução do experimento. Ao Conselho Nacional de Desenvolvimento Científico e Tecnológico - CNPq, pela concessão de bolsa de iniciação científica.

\section{LITERATURA CITADA}

ASSOCIATION OF OFFICIAL SEED ANALYSIS - AOSA. Seed vigor testing handbook. Zürich: 1983. 93 p.

BRASIL. Ministério da Agricultura, Pecuária e Abastecimento. Secretaria de Defesa Agropecuária. Regras para análise de sementes. Brasília, DF: 2009. 399 p.

CARVALHO, N. M.; NAKAGAWA, J. Sementes: ciência, tecnologia e produção. 4.ed. Jaboticabal: Funep, 2000. 588 p.

COSTA, N. P. et al. Antecipação de colheita de sementes de soja através do uso de dessecantes. R. Bras. Sementes, v. 5, n. 3, p. 183-198, 1983. 
COMISSÃO DE QUÍMICA E FERTILIDADE DO SOLO CQFSRS/SC. Manual de recomendações de adubação e calagem para os estados do Rio Grande do Sul e Santa Catarina. Porto Alegre: SBCS - Núcleo Regional Sul, 2004. 394 p.

DALTRO, E. M. F. et al. Aplicação de dessecantes em précolheita: efeito na qualidade fisiológica de sementes de soja.

R. Bras. Sementes, v. 32, n. 1, p. 111-122, 2010.

DELOUCHE, J. C. Seed maturation. In: HANDBOOK of seed technology. Mississipi: Mississipi State University, 1971. p. 17-21.

DELOUCHE, J. C. Pesquisa em sementes no Brasil. Brasília: AGIPLAN, 1975. 47 p.

DURIGAN, J. C.; CARVALHO, N. M. Aplicação em précolheita de dessecantes em duas cultivares de soja (Glycine max (L.) Merrill). I - Efeitos imediatos sobre germinação e produção de sementes. Planta Daninha, v. 3, n. 1, p. 108-115, 1980.

\section{EMPRESA BRASILEIRA DE PESQUISA}

AGROPECUÁRIA - EMBRAPA. Centro Nacional de Pesquisa de Solos. Sistema brasileiro de classificação de solos. - Brasília: Embrapa Produção de Informação/Rio de Janeiro: Embrapa Solos, 1999. 412 p.

\section{EMPRESA BRASILEIRA DE PESQUISA}

AGROPECUÁRIA - EMBRAPA. Tecnologias de produção de soja - Região Central do Brasil, 2005. Londrina: Embrapa Soja, Embrapa Cerrados, Embrapa Agropecuária Oeste, Fundação Meridional, 2005. 242 p.

EMBRAPA SOJA. Soja em números (safra 2010/2011). Embrapa Soja. Disponível em: <http://www.cnpso. embrapa.br/index.php?cod_pai=2\&op_page $=294>$. Acesso em: 21 abr. 2012.

FEHR, W. R.; CAVINESS, C. E. Stages of soybean development. Ames: Iowa Agricultural Experimental Station, 1977. 11 p. (Special Report, 80)

FONSECA, N. Influência da aplicação de paraquat sobre a produção e a qualidade da sementes de soja (Glycine $\max ($ L.) Merrill). 1984. 48 f. Dissertação (Mestrado em Fitotecnia) - Universidade Federal de Viçosa, Viçosa, MG, 1984.

GARCIA, D. C. et al. A secagem de sementes. Ciência Rural, v. 34, n. 2, p. 603-608, 2004.

GIURIZATTO, M. I. K. et al. Efeito da época de colheita e da espessura do tegumento sobre a viabilidade e o vigor de sementes de soja. Ci. Agrotecnol., v. 27, n. 4, p. 771-79, 2003.
GOMES, J. L. L. et al. Efeito da aplicação de gramoxone e do reglone sobre a incidência de patógenos nas sementes de soja. In: CONGRESSO BRASILEIRO DE FITOPATOLOGIA, 15., 1982, São Paulo: Resumos... São Paulo: Sociedade Brasileira de Fitopatologia, 1982.

HARRINGTON, I. F. Seed storage andlogevity. In KOLOWSKI, T. (Ed.). Seed biology. New York: Academic Press, 1972. p. 142-145.

KAPPES, C.; CARVALHO, M. A. C.; YAMASHITA, O. M. Potencial fisiológico de sementes de soja dessecadas com diquat e paraquat. Sci. Agr., v. 10, n. 1, p. 1-6, 2009.

KAPPES, C. et al. Qualidade fisiológica de sementes e crescimento de plântulas de feijoeiro, em função de aplicações de paraquat em pré-colheita. Pesq. Agropec. Tropical, v. 42, n. 1, p. 9-18, 2012.

KRZYZANOWSKI, C. F.; VIEIRA, R. D.; FRANÇA NETO, J. B. Associação Brasileira de Tecnologia de Sementes, Comitê de Vigor de Sementes. Londrina: ABRATES, 1999. 218 p.

LACERDA, A. L. S. et al. Aplicação de dessecantes na cultura da soja: antecipação da colheita e produção de sementes.

Planta Daninha, v. 19, n. 3, p. 381-90, 2001.

LACERDA, A. L. S. et al. Armazenamento de sementes de soja dessecadas e avaliação da qualidade fisiológica, bioquímica e sanitária. R. Bras. Sementes, v. 25, n. 2, p. 97-105, 2003.

LACERDA, A. L. S. et al. Efeitos da dessecação de plantas de soja no potencial fisiológico e sanitário das sementes.

Bragantia, v. 64, n. 3, p. 447-457, 2005.

MARCOS FILHO, J. Produção de sementes de soja. Campinas: Fundação Cargill, 1986. 86 p.

MARCOS FILHO, J. Fisiologia de sementes de plantas cultivadas. Piracicaba: FEALQ, 2005. 495 p.

MAGUIRE, J. D. Speed of germination aid in selection and evaluation for emergence and vigor. Crop Sci., v. 2, n. 1, p. 176-177, 1962.

MALASPINA, I. G. Épocas de aplicação de dessecantes na cultura da soja (Glycine max (L.) Merrill): teor de água, produtividade e qualidade fisiológica das sementes. 2008. $47 \mathrm{f}$. Dissertação (Mestrado em Produção Vegetal) - Universidade Estadual de São Paulo, São Paulo, SP, 2008.

MARCANDALLI, L. H.; LAZARINI, E.; MALASPINA, I. G. Épocas de aplicação de dessecantes na cultura da soja: Qualidade fisiológica de sementes. R. Bras. Sementes, v. 33, n. 2, p. 241-250, 2011. 
McNEAL, F. M. et al. Chemical dessication experiments with hard red spring wheat (Triticum aestivum L.) Agron. J., v. 65, n. 3, p. 451-453, 1973.

NAKAGAWA, J. Testes de vigor baseados na avaliação das plântulas. In: VIEIRA, R. D.; CARVALHO, N. M. Testes de vigor em sementes. Jaboticabal: FUNEP, 1999. p. 49-85.

NAKASHIMA, E. K. et al. Dessecação química na obtenção de sementes de soja com elevada qualidadade fisiológica.

R. Ceres, v. 47, n. 273, p. 483-493, 2000.

PELÚZIO, J. M. et al. Influência da dessecação química e retardamento de colheita na qualidade fisiológica de sementes de soja no sul do Estado do Tocantins. Biosci. J., v. 24, n. 2, p. 77-82, 2008.

RITCHIE, S. W. et al. How a soybean plant developments. Ames: lowa State University of Science and Technology, 1977. 20 p. (Special Report, 53)

ROMAN, E. S.; RODRIGUES, O.; MCCRACKEN, A. Dessecação: uma tecnologia que reduz perdas na colheita de soja. Passo Fundo: Embrapa Trigo, 2001. (Embrapa Trigo. Comunicado Técnico Online, 60). Disponible em: <http:// www.cnpt.embrapa.br/biblio/ p_co60.htm>. Acesso em: 21 abr. 2012.
SÁ, M. E.; LAZARINI, E. Relação entre os valores de condutividade elétrica e níveis de emergência em sementes de diferentes genótipos de soja. Inf. Abrates, v. 5, p. 143, 1995.

SILVA CASTRO, C. A. Produção de n-hexanal e aldeídos totais como índices para avaliar a qualidade fisiológica de sementes de soja (Glycine max (L.) Merrill). 1989. $141 \mathrm{f}$. Tese (Doutorado em Fitotecnia) - Universidade Federal de Viçosa, Viçosa, MG, 1989.

VARGAS, L.; ROMAN, E. S. Resistência de plantas daninhas a herbicidas: conceitos, origem e evolução. Passo Fundo: Embrapa Trigo, 2006. 22 p. (Embrapa Trigo Documentos Online 58). Disponível em: <http:// www.cnpt.embrapa.br/biblio/do/p_do58.htm>. Acesso em: 17 abr. 2012.

VIEIRA, R. D. Testes de condutividade elétrica. In: VIEIRA, R. D.; CARVALHO, N. M. Testes de vigor em sementes. Jaboticabal: FUNEP/UNESP, 1994. p. 103-132.

WHIGAN, D. K.; STOLEER, E. W. Soybean dessication by paraquat, glyphosate and ametryn to accelerate harvest.

Agron. J., v. 71, p. 633, 1979. 